\title{
MAPEAMENTO DO CAMPO TÉRMICO NO CENTRO DE FLORIANÓPOLIS: UMA PROPOSTA METODOLÓGICA - ORGANIZAÇÃO DO BANCO DE DADOS
}

\author{
SOUZA, Fábio Ribeiro - fabiors777@yahoo.combr \\ MENDONÇA, Magaly - magaly@cfh.ufsc.br \\ PAULINO, Luiz Antônio - paulino@cfh.ufsc.br \\ Programa de Pós-graduação em Geografia e Dep. de Geografia \\ UFSC - Universidade de Santa Catarina
}

\begin{abstract}
RESUMO
O presente trabalho aborda uma proposta de organização de um Banco de Dados Geográficos (BDG), dentro de um Sistema de Informação Geográfica (SIG), que propicie a elaboração de mapas temáticos para análise das variações dos dados meteorológicos, dentro do ambiente urbano. Este artigo é fruto de um projeto, que busca tornar aplicável uma proposta metodológica apresentada por Monteiro (1990), o qual foi denominado "Mapeamento do Campo Térmico do Centro de Florianópolis: Uma proposta metodológica", coordenado pela Profa. Magaly Mendonça com a colaboração do Prof. Luiz Antônio Paulino, através do programa FUNPESQUISA 2005/2006 e estendido para 2007/2008 com o nome "Mapeamento do Campo Térmico do Centro de Florianópolis: Etapa avançada de uma proposta metodológica". Estes projetos geraram dados meteorológicos e das funções das edificações urbanas do centro de Florianópolis os quais serviram como base para a estruturação do BDG. Através dos dados disponíveis avaliou-se a estruturação do BDG e de suas possibilidades na geração de produtos cartográficos para futuras análises. Espera-se que com 0 desenvolvimento do SIG proposto neste trabalho, novas pesquisas possam ser produzidas, fomentando o aperfeiçoamento metodológico de estruturação de dados meteorológicos, possibilitando uma interação entre diversos estudos climáticos, como comparações e análises que permitam a construção do entendimento das alterações climáticas produzidas pelo espaço urbano e desta maneira constituir uma ferramenta para gestores do planejamento urbano.
\end{abstract}

Palavras-chave: Sistema de Informação Geográfica. Campo térmico. Clima urbano. Banco de dados geográficos

\begin{abstract}
This paper discusses a proposed of organization of a Geographical Database (GDB), within a Geographic Information System (GIS) which triggers the production of thematic maps for analysis of variations in meteorological data, within the urban environment. This article is the result of a project that seeks to make applicable a methodological proposal by Monteiro (1990), which was called "Mapping of the Thermal Field of Florianópolis' Downtown: A methodological proposal", coordinated by Dr. Magaly Mendonça, through program FUNPESQUISA 2005/2006 and extended to 2007/2008 with the name "Mapping of the Thermal Field of Florianópolis' Downtown: Advanced step of a methodological approach". These projects have generated meteorological data and of the functions of urban buildings from downtown of Florianopolis which served as the basis for structuring the GDB. Using the available data was made an evaluation of the structure of GDB and its possibilities in the generation of cartographic products for future analysis. It is hoped that with the development of the GIS proposed, further research may be produced and so provides the methodological improvement of structure of weather data, allowing an interaction between various climate studies, the possibility comparisons and analysis that help in building of the understanding of climate change produced by the urban space and thus provide a tool for managers of urban planning.

Keywords: Geographic Information System. Thermal field. Urban climate. Geographic database.
\end{abstract}

\section{INTRODUÇÃO}

Este trabalho envolve questões bastante discutidas atualmente, pois trata de um assunto intimamente ligado à qualidade e condição de vida do homem moderno, o clima nas cidades. É nos centros urbanos o lugar onde existe a maior concentração de seres humanos no planeta na atualidade e é também o 
lugar onde ele mais se apropria do sítio e o transforma, sempre em busca de agregar estruturas urbanas que the propicie maior conforto.

É aceito pela comunidade científica que toda ação antrópica gera algum impacto ao meio ambiente e, portanto, não seria errado pensar que na cidade, onde ocorre maior densidade de seres humanos, surgirão os maiores impactos. Seguindo este raciocínio, as áreas urbanas apresentam as maiores alterações do espaço, decorrentes da degradação ambiental, em vários níveis temporais e espaciais (Lombardo, 1985). Estas ações provocam reações da natureza que se manifesta interferindo e interagindo diretamente com o homem urbano. Os fenômenos inter-relacionados como ilha de calor, poluição do ar, chuvas intensas, inundações e deslizamentos passam a fazer parte do cotidiano urbano fazendo com que a população conviva diretamente com os problemas deles decorrentes.

Apesar de vários trabalhos científicos sobre os temas que abordam as relações entre o homem e o meio ambiente, e as consequências destas interações e inter-relações estarem bastante avançadas nos dias atuais, não é uma tarefa fácil mensurar onde, como e com que intensidade o meio ambiente reage às alterações provocadas pela sociedade urbana. Dentre os diversos olhares sobre o tema, muitos trabalhos foram e continuam sendo produzidos buscando compreender aquilo que assume maior importância, as alterações climáticas globais. Alguns destes trabalhos foram dedicados às possíveis alterações sobre o clima nas cidades e é neste sentido que este trabalho se desenvolve.

É possível encontrar características climáticas diferentes, em menor escala, dentro dos centros urbanos, ao mesmo tempo e sob uma mesma condição meteorológica e climática (DUARTE \& SERRA, 2003). Determinadas condições irão formar climas locais específicos dentro da cidade, caracterizando o designado clima urbano. Desta maneira, o clima urbano é definido pelo somatório dos fluxos horizontais e verticais de energia e matéria: os horizontais compostos pelos centros de ação, massas de ar, frentes e ventos locais e os verticais compostos pelo conjunto de fatores como radiação solar, albedo, balanço energético e transmissividade atmosférica (ROSSI \& KRÜGER, 2005).

A urbanização altera significativamente o clima urbano, considerando-se o aumento das superfícies de absorção térmica, impermeabilização dos solos, alterações na cobertura vegetal, concentração de edifícios que interferem nos efeitos dos ventos, combinação da atmosfera através da evaporação dos gases (LOMBARDO, 1985).

A grande dificuldade atualmente está em desenvolver um procedimento metodológico que leve em consideração todas as variáveis e que possa dar conta de mapear essas particularidades climáticas dentro do ambiente urbano. Tal metodologia, além de contribuir para as discussões sobre conforto térmico no ambiente urbano, forneceria subsídio aos gestores da cidade, no planejamento deste ambiente.

Com este objetivo foi proposto o projeto de pesquisa denominado "Mapeamento do Campo Térmico do Centro de Florianópolis: Uma proposta metodológica", 
coordenado pela Dra. Magaly Mendonça em parceria com o Prof. Luiz Antônio Paulino, que desenvolveram e aplicaram uma metodologia para coletar informações que auxiliassem na busca por respostas ao entendimento das possíveis variações térmicas encontradas dentro do centro de Florianópolis. 0 levantamento de dados foi realizado em aulas práticas da disciplina de Climatologia, no Curso de Graduação em Geografia, envolvendo turmas de 40 alunos, que divididos em equipes procederam ao registro de dados meteorológicos em 38 pontos do Bairro Centro, a partir de estações portáteis, além do detalhamento do uso da terra, descrevendo os objetos urbanos contidos em uma quadra de $75 \mathrm{~m}^{2}$ com auxílio de recortes de imagens de satélite e uma planilha quadriculada com escala vertical e horizontal e uma legenda indicativa dos materiais constitutivos das estruturas urbanas e de suas funções. Este trabalho produziu uma enorme quantidade de dados meteorológicos e das funções das edificações, além de informações sobre a circulação de pedestres e de veículos, no centro da capital catarinense, contudo faltava uma metodologia de organização desses dados, de modo a favorecer sua análise.

Este trabalho se insere dentro desta pesquisa, propondo-se uma metodologia de organização dos dados coletados, dentro de uma ordem que possibilite a geração de produtos cartográficos, colaborando com o desenvolvimento metodológico para estudos do mapeamento do campo térmico das cidades. Buscou-se organizar e estruturar os dados, dentro de uma lógica e de um sistema de informação que permita justamente a evolução da pesquisa, fornecendo subsídio técnico para análise dos fenômenos climáticos encontrados. Assim, escolheu-se usar um Sistema de Informação Geográfica - SIG, pois se trata de uma ferramenta de caráter interdisciplinar, própria para produzir material de análise espacial, além de se tratar de uma tecnologia que se apresenta atualmente com o propósito de auxiliar no planejamento de ações e na tomada de decisões. Para a elaboração do SIG foi escolhido o software ArcMap da Environmental Systems Research Institute - ESRI.

\section{2 ÁREA DE ESTUDO}

A área de estudo situa-se no sul do Brasil, na capital do estado de Santa Catarina, na parte mais central do distrito sede do município de Florianópolis, na porção insular, localizada na vertente oeste do Maciço Central, tendo como limites a Avenida Mauro Ramos, que contorna a elevação, e os aterros das baias Norte e Sul, que delimitam o triângulo central, que está localizado dentro do quadrante determinado pelas coordenadas geográficas 27035'2,45"S $48^{\circ} 33^{\prime} 49,3 \mathrm{~W}$ e 27036'17,75"S 48032'31,1"W (Figura 1). 


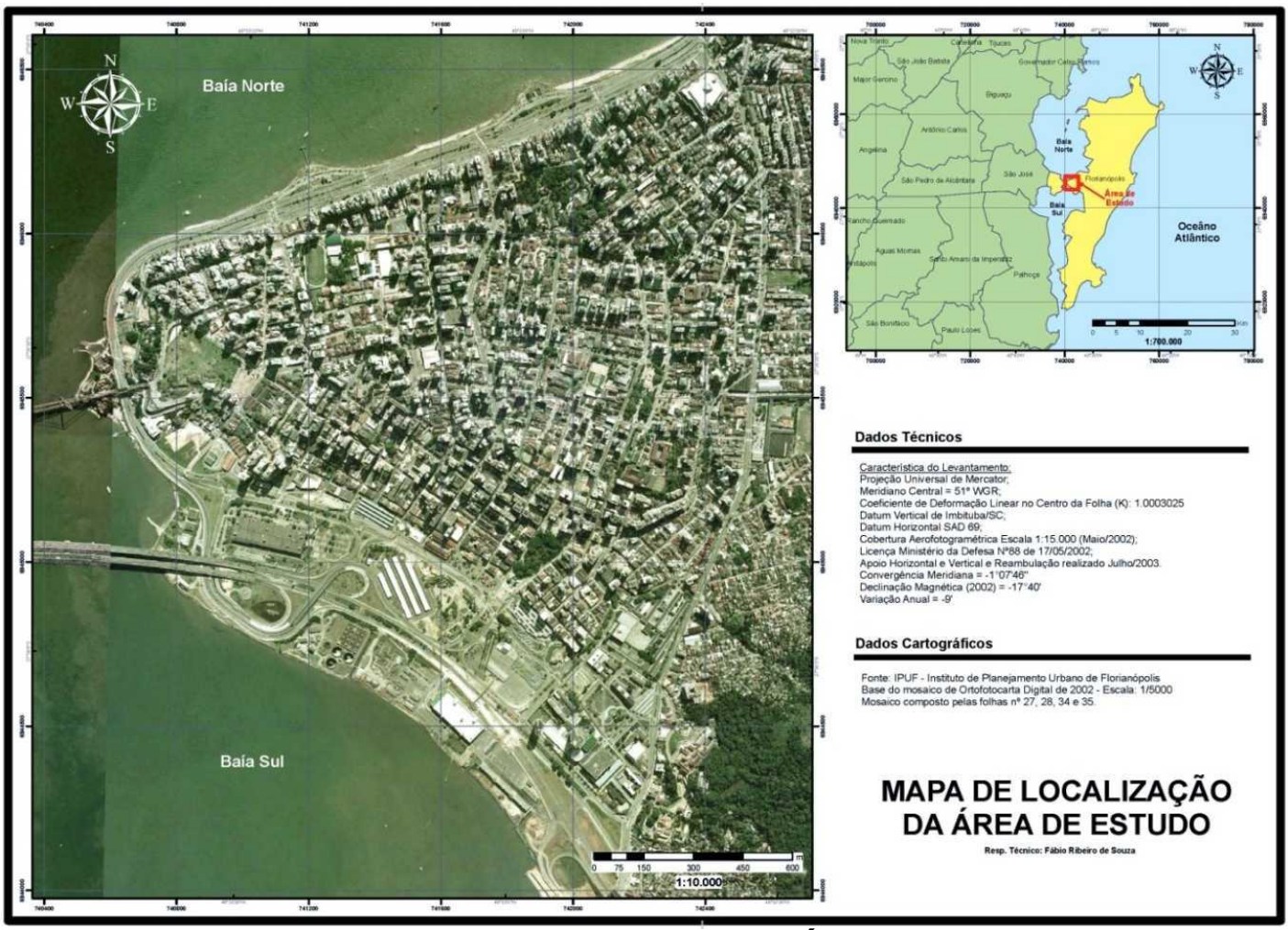

Figura 1 - Mapa de Localização da Área de Estudo

\subsection{Percepções gerais sobre a área de estudo}

A proximidade da ilha de Florianópolis com o continente permitiu a formação das baías norte e sul, formando um grande ambiente estuarino, produzindo um ambiente com condições sedutoras, ricos em recursos faunísticos, bastante apreciados pelos primeiros habitantes (LIMA, 2007). Além disso, a necessidade de encontrar condições geográficas favoráveis à defesa territorial, a maior segurança contra ataques indígenas, a mata aparentemente menos agreste, a possibilidade de fácil instalação portuária e córregos abundantes, serviram como atrativos a ocupação da ilha (VEIGA, 1993). A topografia, formada por colinas com altitude em torno de $25 \mathrm{~m}$ e pequenos vales de vertentes suaves, originados por processos erosivos (HERRMANN, 1989), protegida por um "morro padrasto" convidava à instalação da comunidade, repetindo o modelo de ocupação lusitana aplicado ao litoral brasileiro (VEIGA, 1993).

Nesta área encontram-se rugosidades do modelo de ocupação que data do período de sua colonização e se caracteriza por antigos casarões, ruas estreitas e comércio intenso (Centro Histórico), entremeada ao modelo atual, que transformou os usos e funções destas edificações, que passou da predominância residencial unifamiliar para uma predominância comercial e multifamiliar, com ruas largas, arquitetura moderna e prédios com gabarito de até 18 pavimentos, resultando em uma massa edificada compacta e com poucas áreas livres (BORTOLUZZI, 2004), (BUENO, 2006). 
Devido à alta densidade edificada, a vegetação original foi totalmente suprimida, restando apenas pequenos agrupamentos de árvores, geralmente em praças, e de gramíneas, presentes em canteiros e ao longo das principais avenidas.

Segundo a metodologia proposta por Köeppen, o Estado de Santa Catarina tem clima tipo mesotérmico úmido, variando em subtipos Clima subtropical (Cfa) e Clima temperado ( $\mathrm{Cfb}$ ). Na região da grande Florianópolis encontram-se influencia de ambos os tipos climáticos sendo predominante nas baixas altitudes o clima subtropical Cfa e nas regiões mais elevadas o clima temperado.

Devido sua localização, Florianópolis apresenta clima subtropical ( $\mathrm{Cfa}$ ) com dois períodos quentes (entre $18^{\circ} \mathrm{C}$ e $22^{\circ} \mathrm{C}$ ), um mais quente (acima de $22^{\circ} \mathrm{C}$ ) e outro mais fresco (entre $15^{\circ} \mathrm{C}$ e $18^{\circ} \mathrm{C}$ ) (MONTEIRO, 1963 apud MENDONÇA, 2002).

Quando ocorre uma passagem de frente fria polar, as temperaturas diminuem e o tempo muda bruscamente. Esta passagem, quando ocorre durante o inverno, acarreta em ondas de frio proveniente da massa polar, enquanto que no verão percebe-se sua passagem através da mudança de direção dos ventos, que então sopram do sul, e pela amenização da temperatura. Contudo, ocorre sempre uma elevação da temperatura antes da chegada da frente fria (MENDONÇA, 2002).

As chuvas são geralmente pré-frontais, frontais e pós-frontais, reguladas pela passagem da frente fria polar; as precipitações são bem distribuídas ao longo do ano, contudo, são leves, contínuas e menos abundantes no inverno, e torrenciais no verão, principalmente em fevereiro. Nessa estação ocorrem chuvas convectivas, associadas ao aquecimento do continente, que junto ao litoral, apresenta temperaturas médias máximas, nesse mês, devido ao atraso do aquecimento das águas em relação ao solstício de verão. Durante os anos de El Niño, as temperaturas são geralmente mais altas e o período mais chuvoso, enquanto que quando o fenômeno La Niña atua, o ano tende a ser mais frio e menos chuvoso (MENDONÇA, 2002).

As formas urbanas podem influenciar no clima local, que, dependendo da sua topografia e dos diferentes usos do solo, dá origem a um processo conhecido como corredores de vento e barreiras que podem provocar mudanças na direção e intensidade dos ventos (MORAIS et al., 2007). A proximidade com o oceano faz com que os fluxos de ar, proveniente do mar ao continente durante a noite $e$ do continente ao mar durante o dia, tenham um papel importante na amenização da temperatura local, contudo, as construções verticais presente nas faixas litorâneas, acabam por criar um obstáculo, dificultando a troca de calor (ROMERO et al., 2008). Ao longo da Avenida Beira Mar Norte observa-se a formação de uma barreira para as brisas e ventos, compostas por edifícios construídos em geral com 12 pavimentos, dispostos lado a lado, separados apenas por ruas perpendiculares que canalizam o fluxo de ar. Neste sentido, a intensa verticalização e disposição das edificações da área estudada, cria uma nova topografia sobre a geomorfologia local e altera sua dinâmica microclimática.

Essa geometria urbana aliada a alta densidade de materiais urbanos (concreto, asfalto, etc.) e a nova topografia construída, são responsáveis pela diminuição 
da reflexão do input de radiação de ondas curtas, em comparação, por exemplo, com as áreas rurais, pois parte da radiação refletida pelas superfícies urbanas não chegam a ser devolvida à atmosfera livre por causa da rugosidade da superfície urbana. Desta forma, quanto menor o albedo - parte da radiação solar incidente sobre um corpo que é refletida, maior será a quantidade de energia disponível para absorção e transmissão, aumentando assim, a temperatura superficial dos elementos urbanos, e por fim, aumentando a liberação de calor para o meio externo (COX, 2008).

\section{SISTEMA DE INFORMAÇÃO GEOGRÁFICA}

Para compreender a escolha por adotar o Sistema de Informação Geográfica SIG, como ferramenta principal para o desenvolvimento deste trabalho, é necessário entender dois conceitos que estão intrinsecamente relacionados e que compõe o próprio conceito de SIG, o conceito de Sistema de Informação e de Informação Geográfica.

Um sistema de informação pode distinguir-se de acordo com muitos critérios como domínio, funcionalidade, objetivos e meios, mas é essencialmente caracterizado por dois componentes: um conjunto de dados e um conjunto de meios técnicos, procedimentos e regras capazes de estruturar, relacionar e interpretar esses dados dando-Ihes significado e valor, isto é, transformando-os em informação (TEIXEIRA, 1993). Sendo assim, em um SIG trabalha-se com dados geográficos, que, após processados, são convertidos em informação geográfica, o que seria, recorrendo à etimologia da palavra, informação sobre a Terra (BARBOSA, 2006).

Um sistema de informação geográfica é a combinação de um conjunto de pessoas qualificadas (peopleware), dados espaciais e descritivos, métodos analíticos, software de computador e de hardware, tudo organizado para automatizar, gerenciar e produzir informação através da representação geográfica (ZEILER, 1999).

Estes cinco componentes surgem na literatura, geralmente sobre a forma representativa de uma estrela, ou uma mandala, na intensão de mostrar a interconexão entre todos os componentes, contudo, aqui é representado segundo uma hierarquia, indo do mais importante elemento para o menos importante (HARMON \& ANDERSON, 2003). 


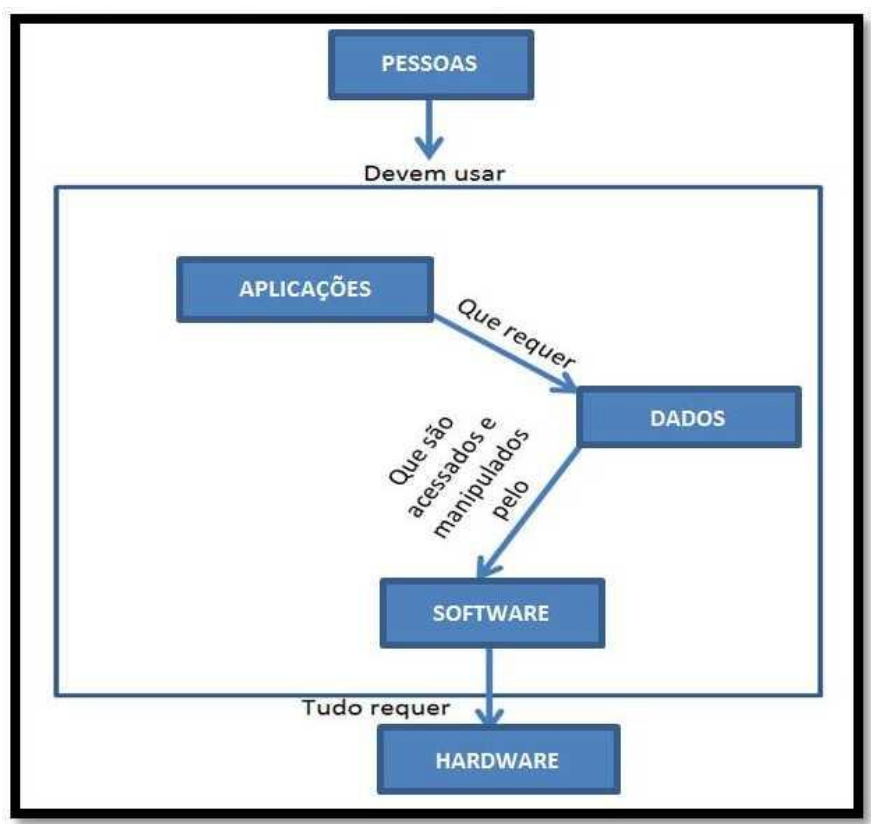

Figura 2 - Ilustração dos elementos que compõe um SIG.

Fonte: Adaptado de Harmon \& Anderson, 2003

As pessoas seriam o componente mais importante, pois o sistema é criado para atender suas necessidades, agilizar seu trabalho e fornecer informações mais consistentes. O processo de concepção e implantação de um SIG começa com as pessoas e suas necessidades e termina nas mãos de quem faz o trabalho. As aplicações vêm em seguida, pois são elas que definem quais trabalhos devem ser feitos. Para todos os sistemas de informações é preciso saber quais aplicações o sistema dará suporte. As aplicações requerem dados para funcionar. Estes são armazenados em bancos de dados aonde o sistema irá, através de um software, acessá-los, gerenciá-los e manipulá-los. A aplicação, o dado e o software, representam o núcleo do SIG, e precisam do hardware para trabalhar, porém devem funcionar em qualquer configuração de hardware, ou seja, este não pode ser um limitador para que o sistema funcione e por isso assume um papel de menor importância (HARMON \& ANDERSON, 2003).

Cada sistema implementa estes componentes de forma distinta, em função de seus objetivos e necessidades, contudo, todos devem estar presentes para se constituir um SIG (CÂMARA, 1995).

Restrições para preservar a integridade do banco de dados geográficos devem ser empregadas na entrada do sistema, seja na alimentação ou atualização dos dados, a fim de preservar a semântica e a qualidade dos dados armazenados. A maioria dos softwares de SIG disponíveis no mercado não apresenta um sistema gerenciador de dados que se preocupe em manter essa integridade e transferem a responsabilidade ao peopleware.

$\mathrm{Na}$ arquitetura destes sistemas não há nenhum controle sobre o relacionamento entre os dados das diversas camadas. A manutenção dos dados não sofre nenhum tipo de restrição, podendo o usuário inserir e excluir colunas de dados 
alfanuméricos ou alterar a topologia dos objetos geográficos de forma absolutamente livre. Desta forma a semântica e a qualidade dos dados armazenados não fica garantida (REZENDE, 2003).

Para a elaboração do SIG, foi utilizado o software ArcMap v9.2 da ESRI Environmental Systems Research Institute, que utiliza um Sistema de Gerenciamento de Banco de Dados Geográficos para armazenar os atributos convencionais dos objetos geográficos na forma de tabela e arquivos para guardar as representações geométricas destes objetos. Os dados são organizados na forma de tabelas onde as linhas correspondem aos dados e as colunas aos atributos. Para cada entidade gráfica inserida no sistema, é imposto um número identificador, utilizado para fazer a ligação lógica com seus respectivos atributos não espaciais armazenados nas tabelas (CÂMARA et al., 2004).

Uma das desvantagens desse sistema é a falta de interoperabilidade entre os dados. Cada sistema cria seu próprio arquivo proprietário sem seguir um formato padrão, o que dificulta a integração destes dados (CÂMARA et al., 2004).

Este trabalho não irá se estender sobre todos os componentes de um SIG, mantendo seu foco apenas sobre a organização dos dados. Neste sentido, optou-se por utilizar um Banco de Dados Geográficos - BDG, que é um módulo do SIG responsável por armazenar os objetos geográficos e campos pertinentes a uma aplicação (THOMÉ, 1998), e na relação da entrada de dados no sistema.

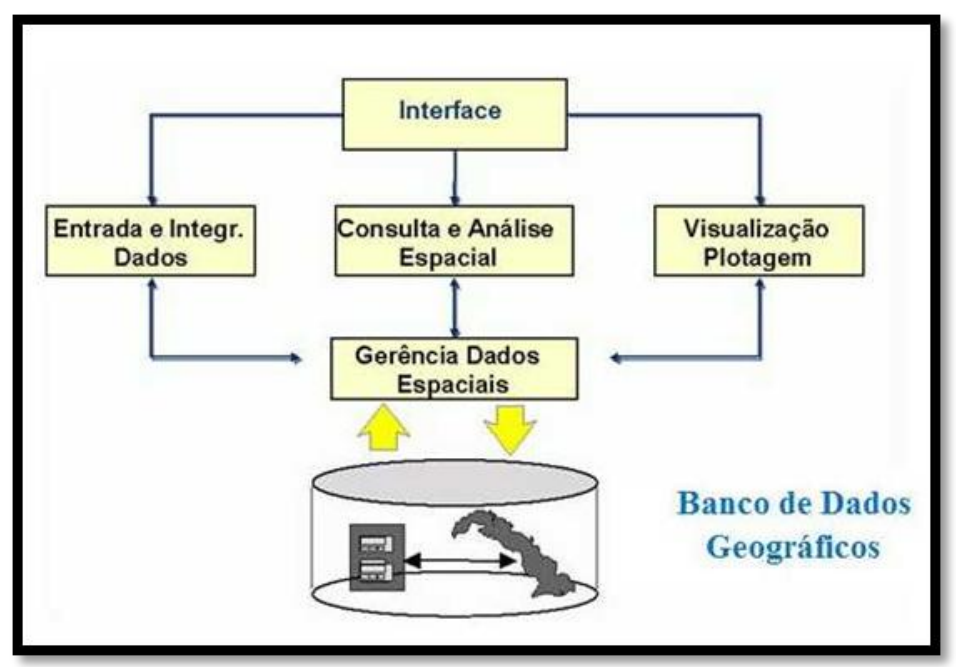

Figura 3 - Relacionamento dos principais componentes de um SIG

Para a concepção da estrutura do banco de dados, deve-se levar em consideração os tipos de dados e modelagens que se deseja fazer. Assim sendo, passar os dados coletados para dentro de um sistema computadorizado é uma tarefa que exige uma cuidadosa atenção por parte de qualquer agente implementador de um SIG, independente de seu domínio em informática. O computador e o espaço real são duas realidades físicas com comportamentos 
totalmente distintos, diferentemente do mapa e do espaço real que, embora distintos, apresentam comportamentos de análise semelhantes.

Para a entrada de um determinado dado no sistema, deve-se escolher entre o modelo raster ou vetorial, a fim de se evitar a redundância de dados. O modelo raster é usualmente aquele que traduz a concepção do espaço como o objeto primário e em que os objetos e atributos constituem as propriedades do lugar. Os dados são atribuídos a unidades de áreas elementares chamada de pixel, com tamanho e formato constante e posicionadas de forma contígua e sequencial, permitindo assim uma representação discreta de todo o espaço. Os atributos podem ser classificados por camadas (layers), em que cada célula existe por si e absorve os atributos inerentes a sua posição e relativos aos respectivos temas. Os objetos não são representados diretamente, mas surgem por análise espacial dos atributos das células. Já o modelo vetorial reforça o conceito de objeto (feature), definindo os dados espaciais e os atributos de cada objeto com interesse relevante para o sistema de informação. Neste modelo as entidades espaciais elementares são objetos suscetíveis de agregação ou desagregação e com tamanhos, formatos e tipos variados. Os três tipos de objetos são: pontos, linhas e polígonos (TEIXEIRA, 1993).

No caso específico, optou-se por utilizar o modelo de dados vetoriais, pois empregam uma estrutura de dados que descreve os objetos, como pontos, linhas e polígonos, por meio das respectivas coordenadas. A definição geométrico-vetorial dos objetos é complementada por uma definição ou classificação de atributos através de uma ligação a tabelas de uma base de dados.

\section{CONCEPÇÃO DO BANCO DE DADOS GEOGRÁFICOS}

No SIG, a compatibilidade da representação do espaço real em um suporte digital, que por sua natureza é limitado, só é possível generalizando ou abstraindo as relações e os elementos-objetos, isto é, criando um modelo de dados capaz de incorporar somente as propriedades relevantes para a aplicação que se objetiva. Pensando assim, em um primeiro momento, fez-se a análise dos dados disponíveis e buscou-se encontrar a melhor maneira de estruturar um banco de dados geográficos para recebê-los, visando a obtenção de um produto cartográfico passível de análise.

Os dados disponíveis foram obtidos em 38 pontos espalhados pela área de estudo, nos quais foram coletados dados de temperatura e umidade do ar, direção e intensidade dos ventos, nebulosidade e número de pessoas e veículos circulando no seu entorno.

A partir da análise dos dados, percebe-se imediatamente que se trata de pontos amostrados e, portanto, nada mais lógico do que representá-los por pontos localizados sobre as mesmas coordenadas geográficas de onde foram obtidos. Para cada dia de coleta foi criada uma tabela de atributos com campos correspondentes para cada dado coletado (ver tabela 1). Além disso, foi 
necessário considerar o fator tempo, o que poderia ter sido feito com a criação de um campo na tabela para o registro do horário de coleta, tendo em vista que foram coletados dados às 6:00h, 9:00h, 15:00h e 21:00h. Como este trabalho tem o intuito de servir a um projeto acadêmico e possuir até certo caráter didático, escolheu-se utilizar uma tabela para cada dia e cada horário. Assim, apesar da multiplicação do número de tabelas, fica mais fácil o entendimento sobre a metodologia criada e também facilita a manutenção, manuseio e complementação do banco por futuros acadêmicos.

Tabela 1 - Exemplo da tabela de atributos para cada dia e hora de coleta de dados

\begin{tabular}{cccccccc}
\hline $\begin{array}{c}\text { Nome } \\
\text { do } \\
\text { Ponto }\end{array}$ & Temperatura & $\begin{array}{c}\text { Umida } \\
\text { de }\end{array}$ & $\begin{array}{c}\text { Direção } \\
\text { do } \\
\text { Vento }\end{array}$ & $\begin{array}{c}\text { Intensidade } \\
\text { do Vento }\end{array}$ & $\begin{array}{c}\text { Nebulosi } \\
\text { dade }\end{array}$ & $\begin{array}{c}\text { Tráfego } \\
\text { de } \\
\text { Pessoas }\end{array}$ & $\begin{array}{c}\text { Tráfego } \\
\text { de } \\
\text { Veículos }\end{array}$ \\
\hline $1 \mathrm{~A}$ & 23,5 & 80 & 90 & 0 & 7 & 0 & 5 \\
\hline $1 \mathrm{~B}$ & 24,5 & 75 & 135 & 2 & 6 & 5 & 10 \\
\hline $1 \mathrm{C}$ & 24,8 & 69 & 275 & 0 & 5 & 4 & 35 \\
\hline $2 \mathrm{~A}$ & 23,4 & 81 & 225 & 3 & 8 & 8 & 40 \\
\hline $2 \mathrm{~B}$ & 23,3 & 89 & 180 & 2 & 8 & 20 & 35 \\
\hline
\end{tabular}

Observando o exemplo acima, percebe-se que os dados referentes à temperatura e umidade do ar armazenam os valores obtidos diretamente a partir dos instrumentos de medição. Os valores de tráfego de pessoas e veículos obtidos através de contagem em campo durante um minuto, também são digitados diretamente na tabela. A direção do vento representa o angulo de inclinação, tendo como referência o norte magnético, cujo valor adotado é zero e considerando o incremento no sentido horário. O valor da intensidade do vento foi obtido através da escala de Beaufort. Para a nebulosidade foi considerada uma escala onde o valor zero representa céu limpo e oito totalmente encoberto.

Essa estrutura permite realizar interpolações, criando uma espacialização da temperatura, da umidade do ar e da nebulosidade sobre a área estudada.

Para efetuar alguma análise sobre o comportamento do clima urbano é necessário também gerar um modelo digital do terreno.

O modelo digital de terreno - MDT é construído a partir de uma simbolização matemática (geométrica, estatística, etc.) e consequentemente suas relações de correspondência com a realidade ocorrem sob fórmulas matemáticas, fornecendo ao modelo a vantagem de ter a capacidade de verificação e repetição do resultado final (FELICÍSIMO, 1992).

Apesar de ser uma área de grande importância socioeconômica para o município de Florianópolis, existem poucos dados referentes à topografia do centro da cidade. O único levantamento topográfico existente obtido foi o produzido em 1979 e fornecido pelo Instituto de Planejamento Urbano de Florianópolis - IPUF. Foi necessário a escanerização (processo onde é criado um arquivo de imagem a partir de um documento impresso) desse mapa com as curvas de nível para 
posteriormente digitalizá-las, através do método de vetorização supervisionada, com o auxilio de um software de CAD, o MicroStation v8.

As curvas de nível estavam representadas de 10 em 10m, impossibilitando uma melhor caracterização da geomorfologia da região, pois na área estudada existem poucas elevações e variações altimétricas. Como é de extrema importância a caracterização do relevo do sítio estudado, fez-se necessário um trabalho de suavização da representação do relevo criando uma base digital com curvas de nível de metro em metro, através da utilização de um software chamado Topograph.

Antes de criar o MDT a partir das novas curvas de nível, foi necessário passar o arquivo por uma verificação topológica utilizando o software ArcMap. A topologia, segundo Thomé (1998), é um processo matemático para definir explicitamente os relacionamentos espaciais e no caso dos mapas, a topologia define conexões entre suas entidades. Desta maneira a verificação topológica do arquivo contendo as curvas de nível garante sua integridade relacional eliminando os possíveis erros decorrentes do processo de importação dos arquivos vetoriais oriundos de programas do tipo CAD para arquivos no formato shape, utilizados nos programas de SIG.

Após a verificação topológica, o arquivo foi utilizado para gerar o arquivo TIN Triangulated Irregular Network, criando o MDT. A criação do TIN permite que as informações morfológicas importantes sejam consideradas durante a criação da grade triangular, possibilitando assim modelar a superfície do terreno preservando essas feições geomorfológicas da superfície (FELGUEIRAS \& CÂMARA, 2004).

Com estes elementos, associado a uma imagem de satélite, já é possível produzir alguns mapas com elementos que permitem uma primeira análise sobre os fenômenos encontrados. Um exemplo dessa possibilidade é demonstrado na figura abaixo (Figura 4), elaborada a partir da interpolação dos dados de temperatura sobre a imagem de satélite do centro de Florianópolis. 


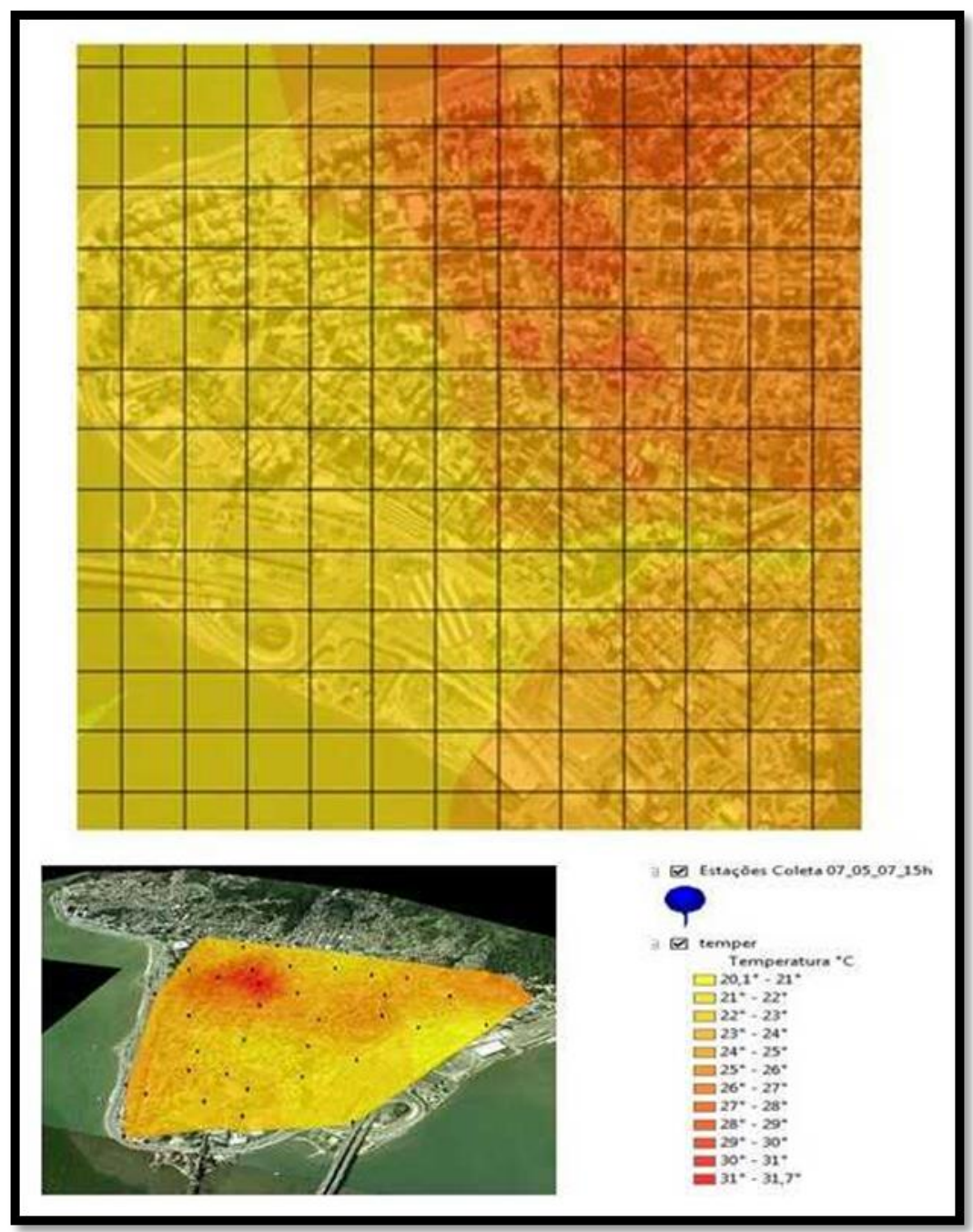

Figura 4 - Ortofotocarta digital (IPUF, 2002) com sobreposição dos dados de temperatura coletados em 07/05/2007 às 15:00h, em vista de topo e em perspectiva.

Fonte: SOUZA, 2008.

Em uma rápida análise da figura produzida, percebe-se que as áreas abertas, onde há uma menor concentração de edifícios, parte SW do sítio analisado, apresentou a temperatura mais baixa, contrastando com a região $\mathrm{N}$ e $\mathrm{NE}$, mais edificada e mais quente. Outro fator interessante são as variações de temperatura apresentadas seguindo a orientação do sistema viário. Esse fato pode representar uma provável influência dos fluxos de ar. Na região mais edificada, os ventos são barrados e canalizados pelas ruas, produzindo corredores frescos que penetram nas áreas quentes, produzidas pela maior concentração de edifícios. Já na região menos edificada, os ventos sofrem menores interferências, podendo penetrar mais facilmente no interior da área de 
estudo e assim, produzindo uma região com temperaturas mais homogêneas e amenas.

\section{Considerações e recomendações}

A qualidade do material gerado pelo SIG depende muito da maneira com que os dados são obtidos e/ou produzidos. Também está relacionado com a estrutura do banco de dados, pois é ela que irá permitir a interoperabilidade relacional dos dados, possibilitando a produção cartográfica de mapas temáticos para análise, ou seja, todo o processo, desde a origem até a organização dos dados, está diretamente relacionado com as possibilidades, precisão e qualidade dos mapas temáticos.

Neste trabalho, a estruturação dos dados e sua forma cartográfica representacional são sugeridas como sendo uma possibilidade, mesmo que simplória, para a geração de produtos de análises futuras, em busca de maiores esclarecimentos sobre o comportamento térmico da cidade. Faz parte de um projeto ambicioso, que procura entender a variação térmica de áreas urbanas, e que está em sua fase inicial. Obviamente, a estrutura proposta pode sofrer alterações no decorrer do desenvolvimento do projeto, e, por isso propôs-se aqui manter o banco de dados mais flexível possível, sem perder sua integridade.

Com essa organização, podem-se produzir mapas temáticos diversos, como por exemplo: hipsométrico; de declividades; de exposição; variação térmica; variação da umidade; concentração de veículos e pessoas; e direção dos ventos. A partir desses mapas, outros poderão ser criados com o cruzamento dos dados. É neste sentido que o SIG se destaca como ferramenta de produção cartográfica temática para estudos e análises, na tentativa de responder a questões como essas: Será que áreas mais quentes da cidade, são aquelas onde se concentram maior número de prédios? Poderá a pouca variação altimétrica da cidade influenciar a diferenciação térmica encontrada? Qual a influência da circulação de pessoas e veículos na variação térmica? O quanto interfere na distribuição térmica, o tempo de exposição das edificações à radiação solar? Qual é a importância da direção dos ventos na distribuição da temperatura, dentro da cidade? Essas e outras tantas questões ficarão abertas até que se desenvolvam as novas etapas do projeto.

Na figura 4, produzida para demonstrar as possibilidades de aplicação do SIG, é possível notar a variação na distribuição da temperatura e sua possível relação com o papel das vias de circulação de automóveis, da densidade das edificações, da ausência da vegetação, dos sentidos das brisas e direção dos ventos. Contudo, estas relações ainda não foram analisadas. 
São nos cruzamentos destes elementos que se buscarão as respostas para as variações do campo térmico do centro de Florianópolis e neste sentido, a organização do banco de dados geográficos aqui proposta, subsidiará análises profundas através de seus mapas temáticos.

Devido à grande complexidade, frente à própria condição especial da área de estudo, pelo fato de ser uma ilha, de sofrer interferências climáticas em função da proximidade com o mar, de estar localizado em uma região que tem seu clima regido pelas principais forças macro-climáticas da América do Sul, transforma este projeto em um grande laboratório que poderá servir como exemplo para muitas outras cidades.

Desta forma, espera-se que este trabalho instigue novos estudos científicos e aperfeiçoamentos técnicos, aprimorando cada vez mais essa ferramenta poderosa que é o SIG, sempre com o intuito de melhorar a qualidade de vida da sociedade, atualmente concentrada no meio urbano.

\section{REFERÊNCIAS}

BARBOSA, Delfim. F.A.M. O sistema de informação geográfica e a atribuição do benefício: A vinha na região demarcada do Douro. Lisboa, 2006. 114 f. Dissertação (Mestrado em Ciência e Sistemas de Informação Geográfica) - Instituto Superior de Estatística e Gestão de Informação, Universidade Nova de Lisboa.

BORTOLUZZI, S. D. Caracterização das funções e padrões de uso e ocupação do solo no centro de Florianópolis (SC). Florianópolis, 2004. 174 f. Dissertação (Mestrado em Engenharia Civil) - Universidade Federal de Santa Catarina.

BUENO, A. P. Patrimônio Paisagístico e Turismo na Ilha de Santa Catarina: A Premência da Paisagem no Desenvolvimento Sustentável da Atividade Turística. São Paulo, 2006. 374 f. Tese (Doutorado em Projeto de Arquitetura) - Faculdade de Arquitetura e Urbanismo, Universidade de São Paulo.

CÂMARA, G. Modelos, linguagens e arquiteturas para banco de dados geográficos. Tese de Doutorado. Instituto Nacional de Pesquisas Espaciais, 1995. Disponível em: <http://www.dpi.inpe.br/teses/gilberto/>. Acesso em: 10 de outubro de 2011.

CÂMARA, Gilberto; MONTEIRO, Antônio M.; MEDEIROS, José S. de. Introdução à Ciência da Geoinformação. São José dos Campos, INPE, 2004. Disponível em: <http://www.dpi.inpe.br/gilberto/livros.html>. Acesso em: 15 de setembro de 2011

COX, Elisa P. Interação entre clima e superfície Urbanizada: o caso da cidade de Várzea Grande/MT. Mato Grosso, 2008. 142 f. Dissertação (Mestrado em Física e Meio Ambiente) - Universidade Federal de Mato Grosso. 
DUARTE, Denise Helena S; SERRA, Geraldo G. Padrões de ocupação do solo e microclimas urbanos na região de clima tropical continental brasileira: correlações e proposta de um indicador. Revista da ANTAC - Ambiente Construído, Porto Alegre, v.3, n.2, p. 7-20, abr./jun. 2003.

FELGUEIRAS, Carlos Alberto. Modelagem Numérica de Terreno. In: CÂMARA, Gilberto; DAVIS, Clodoveu; MONTEIRO, Antônio Miguel Vieira. Introdução à Ciência da Geoinformação. São José dos Campos: INPE, 2004.

FELICÍSIMO, Angel M. Aplicaciones de los modelos digitales del terreno en las ciencias ambientales. Oviedo, 1992. 235 f. Tese (Doutorado em Ciências) - Instituto de Recursos Naturais e Ordenação do Território, Universidade de Oviedo.

HARMON, John E.; ANDERSON, Steve J. The Design and Implementation of Geographic Information Systems. New Jersey: Wiley \& Sons, 2003. 264 p.

HERRMANN, Maria L. de P. Aspectos Ambientais da Porção Central da Ilha de Santa Catarina. Florianópolis, 1989. 228 f. Dissertação (Mestrado em Geografia) - Universidade Federal de Santa Catarina.

LIMA, Débora da R.R. Ilha de Santa Catarina: desenvolvimento urbano e meio ambiente. Florianópolis: Letras Contemporâneas, 2007. 240p.

LOMBARDO, M. A. IIha de Calor - O Exemplo de São Paulo. São Paulo: Ed. Hucitec, 1985. 244p.

MENDONÇA, Magaly. A dinâmica têmporo-espacial do clima subtropical na região conurbada de Florianópolis/SC. São Paulo, 2002. 343 f. Tese (Doutorado em Geografia) - Faculdade de Filosofia Letras e Ciências Humanas, Universidade de São Paulo.

MORAIS, Laílson S., SILVA, Paulo Cesar M. \& MEDEIROS, Wendson D. A. Análise do processo de verticalização na área urbana do Município de Mossoró/RN: aspectos jurídicos e ambientais. Revista verde de agroecologia e desenvolvimento sustentável Grupo Verde de Agricultura Alternativa GVAA v.2, n.2, p.171-182 Jul/dez. 2007.

REZENDE, Welson G. Modelagem e Integridade dos Dados Geográficos. Apostila do Curso de Geoprocessamento - UFMG. Belo Horizonte, Novembro, 2003.

ROMERO, Hugo; MOLINA, Melandra; VÁSQUEZ, Alexis; SMITH, Pamela. El clima urbano del Puerto de Valparaíso: construcción social del espacio en ciudades costeras. Revista da Faculdade de Letras da Universidade do Porto Geografia. II Série, vII,2008. p108-126.

ROSSI, Francine A. \& KRÜGER, Eduardo L. Análise da variação de temperaturas locais em função das características de ocupação do solo em Curitiba. Revista RA 'E GA. Curitiba, n. 10, p. 93-105, 2005.

SOUZA, Fábio R. Mapeamento do Campo Térmico no Centro de Florianópolis: Uma proposta metodológica - Organização do Banco de Dados. 2008. 82 f. Monografia (Graduação em Geografia) - Universidade Federal de Santa Catarina. 
TEIXEIRA, Óscar C. SIG - Sistema de Informação Geográfica. Porto, 1993. 107 f. Dissertação (Mestrado em Engenharia Eletrotécnica e Computadores) Faculdade de Engenharia da Universidade do Porto.

THOMÉ, Rogério. Interoperabilidade em Geoprocessamento: Conversão entre modelos conceituais de sistemas de informação geográfica e comparação com o padrão open GIS. São José dos Campos, 1998. 199p. Dissertação (Mestrado) - Instituto Nacional de Pesquisas Espaciais. Disponível em: < http://www.dpi.inpe.br/teses/thome/>. Acesso em: 10 de outubro de 2011.

VEIGA, Eliane V. da. Florianópolis: Memória Urbana. Florianópolis: Editora da UFSC e Fundação Franklin Cascaes, 1993. 390p.

ZEILER, Michael. Modeling Our World - The ESRI Guide to Geodatabase Design. Redlands, California: Ed. Environmental Systems Research Institute, 1999. p.201 